MIDAS

Museus e estudos interdisciplinares

$12 \mid 2020$

Varia

\title{
A Coleção Moderna do Museu Calouste Gulbenkian durante o PREC
}

The Modern Collection of the Calouste Gulbenkian Museum during the PREC (ongoing revolutionary process)

\section{Filipa Coimbra}

\section{OpenEdition}

\section{Journals}

Edição electrónica

URL: https://journals.openedition.org/midas/2396

DOI: $10.4000 /$ midas. 2396

ISSN: 2182-9543

Editora:

Alice Semedo, Paulo Simões Rodrigues, Pedro Casaleiro, Raquel Henriques da Silva, Ana Carvalho

\section{Refêrencia eletrónica}

Filipa Coimbra, «A Coleção Moderna do Museu Calouste Gulbenkian durante o PREC», MIDAS [Online], 12 | 2020, posto online no dia 15 dezembro 2020, consultado no dia 06 março 2022. URL: http:// journals.openedition.org/midas/2396 ; DOI: https://doi.org/10.4000/midas.2396

Este documento foi criado de forma automática no dia 6 março 2022.

\section{c) (†)(2)}

Midas is licensed under a Creative Commons Attribution-NonCommercial-ShareAlike 3.0 International License 


\title{
A Coleção Moderna do Museu Calouste Gulbenkian durante o PREC
}

\author{
The Modern Collection of the Calouste Gulbenkian Museum during the PREC \\ (ongoing revolutionary process)
}

Filipa Coimbra

\section{NOTA DO EDITOR}

Artigo recebido a 04.10.2019

Aprovado para publicação a 19.07.2020

\section{Introdução}

1 A formação de coleções é, no âmbito da museologia em Portugal, uma área de estudo ainda pouco aprofundada. A necessidade de divulgação de estudos atualizados sobre as principais coleções do país só recentemente tem vido a merecer um maior compromisso (Pinho 2013; Duarte 2017). A relevância museológica, sociológica e artística da Coleção Moderna do Museu Calouste Gulbenkian tem vindo a ser salientada por vários autores (Ribeiro 2007; Silva 2014; Maurício 2016). No entanto, uma investigação mais sistemática à constituição e desenvolvimento do acervo, sobretudo nos anos ulteriores à Revolução dos Cravos, está ainda por realizar. É desta lacuna que parte o presente estudo. Através da pesquisa ao fundo do Serviço de Belas-Artes (SBA), aos Arquivos Gulbenkian e ao inventário digital da coleção, analisou-se a evolução da coleção no período em apreço, recorrendo-se, para o efeito, a periódicos e a estudos de referência (Pinharanda 1995; Nogueira 2009; Silva, Candeias e Ruivo 2009). Procurando revisitar um período ainda pouco estudado pela historiografia, bem como um acervo essencial para a história de arte e para a institucionalização da arte moderna e contemporânea portuguesas, procurou-se compreender as movimentações da Fundação 
Calouste Gulbenkian (FCG) num ambiente cultural e artístico de grande agitação política e social (1974-1977).

Logo nos seus primeiros anos de atividade, para além das várias iniciativas que promoveu no meio artístico português, a FCG decidiu adquirir obras de arte como forma de auxílio direto aos artistas (Oliveira 2013). Procurando não se comprometer com uma política aquisitiva definida, a FCG orientou, quase exclusivamente, as suas primeiras decisões de compra para obras apresentadas nos certames que promovia, subsidiava ou sobre os quais tinha algum tipo de responsabilidade, nomeadamente as exposições dos seus bolseiros. Progressivamente, e sobretudo a partir da segunda metade década de 1960, a Fundação viria a mostrar maior disponibilidade para o alargamento dos seus circuitos de receção e aquisição de obras de arte.

Observando o relacionamento da FCG com o meio artístico português, a consulta das fontes primárias revelaria um dado inédito nas práticas aquisitivas da FCG: a celebração de um acordo de compra de obras de arte com a Sociedade Nacional de Belas-Artes (SNBA), que vigoraria ente 1975 e 1977. Esta situação excecional suscitou algumas questões de investigação que este artigo procurará analisar. Desde logo, procurar-se-á perceber que motivações desencadearam a celebração do acordo e de que forma contribuiu para o enriquecimento do acervo. Neste sentido, importa aferir se a decisão de compra de obras de arte terá tido como único propósito colmatar a falta de representatividade de alguns artistas no acervo, ou se compreenderia uma estratégia mais lata, de aliança, num período de convulsão e reorganização social, de destituições, substituições, extinções de cargos e saneamentos políticos. Para dar resposta a estas questões, tornou-se necessário, num primeiro momento, compreender a evolução da relação da FCG com a SNBA até 1975, para depois se analisar a conjuntura política e social no período em que vigorou o acordo, às quais se seguiu a análise histórica e artística das obras incorporadas.

\section{A cooperação institucional entre a Fundação Calouste Gulbenkian e a Sociedade Nacional de Belas-Artes (1957-1974): parcimónia aquisitiva}

4 A cooperação institucional entre a FCG e a Sociedade Nacional de Belas-Artes (SNBA) remonta ao início da atividade da Fundação, numa altura que procurava posicionar-se no meio artístico nacional. Nos anos que antecederam a inauguração da Sede e Museu da Fundação (1969), a FCG recorreu às instalações da SNBA para executar o seu programa expositivo (I Exposição de Artes Plásticas da FCG, 1957; Arte Britânica do Século $X X, 1962)$, assumindo, em contrapartida, o patrocínio de obras de requalificação das instalações da SNBA.

5 Frequentadores assíduos dos certames na Sociedade, os dirigentes da FCG só pontualmente viriam a adquirir obras de arte nessas ocasiões. Embora pouco significativo quantitativamente, do conjunto das obras adquiridas entre 1957 e 1974, destacam-se alguns dos artistas fundamentais para a compreensão da arte portuguesa da segunda metade do séc. XX, designadamente Paula Rego, Joaquim Rodrigo, Júlio Pomar, Manuel Baptista, António Palolo, Eduardo Nery, Luís Noronha da Costa ou Artur Rosa. Importa ressalvar que se trata, sobretudo, de aquisições indiretas, que não 
correspondiam à programação expositiva oficial da SNBA, contando, contudo, com a sua intermediação.

6 Até ao final da década de 1950, é evidente a parcimónia das práticas aquisitivas da FCG em relação às exposições e salões oficiais da SNBA, não havendo registo de qualquer compra nos Salões de Arte Moderna (1958-1963), o que não deixa de ser curioso, uma vez que, na linha de orientação seguida pela FCG, haviam afastado académicos e artistas afins ao tardo-naturalismo, o que talvez pressupusesse um maior interesse aquisitivo. A FCG abster-se-ia também de comprar na exposição 50 Artistas Independentes (SNBA, 1959), organizada por um grupo de artistas opositores às iniciativas do Secretariado Nacional de Informação (SNI), que inauguraria, no mesmo dia, no Palácio Foz, o I Salão dos Novíssimos. Anos mais tarde, em 1965, a FCG viria a adquirir um conjunto de obras no âmbito da Exposição dos Artistas Premiados nos Salões Novíssimos.

7 A explicação para este aparente desinteresse está, porventura, na necessidade da FCG, no final dos anos 1950, se estruturar internamente e construir uma posição singular que sobressaísse na cultura artística nacional (Oliveira 2013). Para tal, havia que atuar de forma autónoma, evitando possíveis filiações ou relacionamentos institucionais privilegiados. Por outro lado, ao determinar as aquisições como medida de auxílio aos artistas, a FCG procurou fazê-lo, preferencialmente, e sobretudo nos primeiros tempos, diretamente aos artistas, nas exposições que promovia ou patrocinava, furtando-se a possíveis clientelismos.

O «período de maior importância da Sociedade Nacional, na história das artes em Portugal» (Pena 1994, s/p) surgiria com a eleição de Francisco Conceição Silva para a presidência da SNBA, em 1964, bem como de um novo Conselho Técnico. ${ }^{1}$ A definição de uma nova estratégia programática, a designação do crítico de arte Fernando Pernes para o cargo de secretário-geral e a inauguração da Galeria de Arte Moderna (1965) contribuíram para a modernização da SNBA, reaproximando artistas, que, progressivamente, se haviam distanciado dos salões oficiais (Tavares 2006). Ao contrário do que seria de prever, esta renovação da SNBA não refletiu uma maior regularidade aquisitiva por parte da FCG. Os dados recolhidos evidenciam uma ponderação semelhante à mantida nos primeiros anos, pese embora pareçam resultar de escolhas mais ecléticas, fundamentadas na originalidade e atualidade das propostas

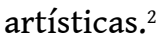

9 Este seria também o período em que a FCG iniciaria a colaboração com o Estado e com o SNI na organização de representações internacionais de arte portuguesa (Afonso 2018). ${ }^{3}$ Esta articulação é demonstrativa do dinamismo - e equilibrismo - das relações institucionais da FCG. Este desígnio de internacionalização artística traduzia-se, quase sempre, em oportunidades de aquisição de obras de arte de artistas contemporâneos, nomeadamente, através da SNBA. ${ }^{4}$

10 O final da década de 1960 e o início da seguinte, seriam marcados, no domínio das aquisições da FCG, por uma redefinição da estratégia e política aquisitiva (Silva 2014), que se tornará mais eclética e cirúrgica, de forma a assegurar uma genealogia firmada em artistas consagrados ou de mérito artístico internacionalmente reconhecido (Amadeo de Souza-Cardoso, Eduardo Viana, Maria Helena Vieira da Silva). Esta opção arredava, automaticamente, a SNBA do seu circuito de compras. 
11 A irregularidade aquisitiva da FCG nos períodos de revitalização artística das exposições oficiais da SNBA viria a contrastar fortemente com o acordo que as duas instituições celebrariam, no pós-25 de Abril.

\section{0 regime democrático e o novo xadrez artístico nacional: a aproximação entre a Fundação Calouste Gulbenkian e a Sociedade Nacional de Belas-Artes}

12 À medida que a FCG foi fortalecendo a sua posição no panorama artístico nacional, com um programa expositivo mais definido, uma sede, um museu e espaços próprios para exposições temporárias (1969), afirmava-se publicamente como uma referência artística, com capacidade - económica e expertise - de articulação com os vários agentes culturais (SNBA, "Gravura", Secção Portuguesa da Associação Internacional de Críticos de Arte/AICA) e com o próprio Estado (SNI; Secretaria de Estado da Informação e Turismo - SEIT). O incremento do colecionismo e do mercado da arte, pelo desenvolvimento de um circuito galerístico mais expressivo e pela profissionalização da crítica da arte, principalmente durante a segunda metade da década de 1960 e início da década seguinte (Pena 1994; Macedo 2009), contribuiu para aliviar o escrutínio sobre a prática colecionista da FCG, que procurava manter uma posição conciliatória face às várias tendências artísticas do séc. XX. Com a conquista da democracia, em 1974, e no decorrer do processo revolucionário, perscrutando a nova realidade do país, a FCG procuraria (re)estruturar relações entre os antigos e novos poderes artísticos e culturais.

13 Nas vésperas da Revolução, a economia portuguesa atingiu níveis de inflação excecionais, afetada pelos efeitos da crise monetária internacional de 1971, tendo sido ainda amplificados pela crise petrolífera de 1973, aos quais acrescia ainda o impacto financeiro da guerra colonial (Macedo 2009; Varela et al. 2015). Após a Revolução dos Cravos, os combates ideológicos contra os efeitos na produção artística da lógica mercantilista do comércio de arte (Silva 2009) aliados à nacionalização da banca conduziram à fuga das elites e à dispersão, e exportação ilícita de importantes coleções de arte (Pinho 2013)..$^{5}$ A generalização dos regimes de exclusividade, a inflação das transações de obras de arte moderna, aliados à conjuntura económica desfavorável contribuíram para o encerramento de um número significativo de galerias e para a quase estagnação do mercado da arte (Pena 1994; Afonso e Fernandes 2019).

14 Afetada pela conjuntura económica de grande instabilidade, a SNBA - que garantia a sua subsistência financeira pelas contribuições mensais dos artistas associados, pelas comparticipações em vendas e mediante subsídios e doações - subsistiria, apesar dos constrangimentos orçamentais, como um polo agregador de artistas e movimentos de artistas. ${ }^{6}$ Também no âmbito da programação expositiva da SNBA se fez sentir este ambiente participativo, que procurava auscultar os artistas sobre a atualidade da criação artística contemporânea (Tavares 2006). Esta nova oferta expositiva da SNBA correspondia ao reduto das exposições de qualidade que surgiram no pós-revolução (Silva 2009).

15 O período foi igualmente marcado pela agitação e pelos excessos dos momentos revolucionários que, no meio artístico, conduziram à oposição e contestação entre grupos de artistas, críticos de arte e a tutela (Movimento das Forças Armadas - MFA), 
trazendo à tona novas e velhas contendas, bem como receios de instrumentalização artística. A administração da FCG seria também confrontada com a inflexibilidade das Comissões de Trabalhadores, que exigiam saneamentos políticos e a participação direta na gestão da FCG (Ferreira 2007; "Fundação Gulbenkian. A Administração Dificulta o Saneamento" 1975). José Azeredo Perdigão (1896-1993) responderia com a prudência que o momento exigia, defendendo a autonomia da Fundação e atuando, cirurgicamente, na afirmação do lugar incontestável da FCG enquanto instituição mecenática, desde logo evidente nestas suas palavras:

[...] Entretanto, o que haveria a fazer era procurar resistir aos embates das paixões e dos apetites, numa palavra, sobreviver, falando o menos possível e mostrando, mais por actos que por palavras, o nosso firme propósito de salvaguardar os interesses superiores da Instituição [...]. [N]os sectores das artes, das letras, da educação e da cultura, em países mais ou menos ricos, mais ou menos desenvolvidos, com governos socialistas ou sociais-democratas, continuará a haver lugar para o mecenato. (Perdigão 1976, 14)

Estará, porventura, ligada a esta estratégia de afirmação mecenática o protocolo, inédito no âmbito da política de incorporações da FCG, celebrado com a SNBA (Arquivos Gulbenkian 1975b) que aprofundava a relação colaborativa entre as duas instituições. Simultaneamente, ao comprar exemplares à SNBA, prestava um duplo auxílio, aos artistas e à instituição. A necessidade de reforço de parcerias institucionais e a perceção de que a SNBA acolhia um significativo número de artistas opositores ao regime anterior, alinhados com o MFA, contribuíram para a celebração deste acordo. A participação ativa que a SNBA assumia nos debates em torno das novas políticas culturais a adotar pelo recém-conquistado regime democrático (Comissão Consultiva para as Artes Plásticas - CCAP da Direcção-Geral da Cultura Popular e Espectáculos do Ministério da Comunicação Social - MCS; ${ }^{7}$ Movimento Democrático dos Artistas Plásticos - MDAP) asseguravam as vantagens desta aliança.

\section{0 acordo de compras pela Fundação Calouste Gulbenkian em exposições promovidas pela Sociedade Nacional de Belas-Artes (1975-1977)}

No início de 1975, Rui Mário Gonçalves (1934-2014), então vice-presidente da Direção da Sociedade, inquiriu a FCG sobre a possibilidade de reserva e aquisição obras de arte da exposição Figuração-Hoje?, que inauguraria brevemente na SNBA (Arquivos Gulbenkian 1975a). O acolhimento desta proposta daria o mote para a concretização de um acordo, sem precedentes, de aquisição de obras de arte em exposições promovidas pela SNBA, que vigoraria entre os anos de 1975 e 1977. O contacto informal existente entre estas direções, assim como o alinhamento e convívio decorrente da participação das duas instituições no âmbito da CCAP, favoreceu, presumivelmente, a materialização deste acordo.

Houve, no entanto, outras motivações circunstanciais que pesaram na decisão, nomeadamente, a oportunidade de a FCG comprar obras de arte no âmbito das poucas exposições bem organizadas e participadas no período, com o intuito de preencher lacunas do acervo da FCG. A representatividade de artistas contemporâneos da coleção necessitava de ser reforçada, dado que se perspetivava, para daí a poucos meses, a realização, a convite do Musée d'Art Moderne de la Ville de Paris, da primeira 
exposição oficial de arte portuguesa contemporânea a ser mostrada no estrangeiro após o 25 de Abril. ${ }^{8}$ Tutelada pelo MCS, a organização da exposição caberia à CCAP, que contava com a FCG como a grande financiadora desta iniciativa, disponibilizando um orçamento de $900000 \$ 00$ e fazendo-se ainda representar enquanto membro integrado da CCAP (Arquivos Gulbenkian 1975d). ${ }^{9}$

Fundamentada nestes pressupostos, e considerando o "alto nível atingido" por aquela exposição-inquérito, os responsáveis dos Serviços de Belas-Artes e de Exposições e Museografia, Artur Nobre de Gusmão, Fernando de Azevedo e José Sommer Ribeiro propuseram ao Conselho de Administração da FCG um reforço de aquisições (Arquivos Gulbenkian 1975c, 1). No entender dos signatários da informação a SNBA, «a mais genuína e representativa associação de classe dos artistas plásticos em Portugal», era «digna de apoio e de encorajamento» (Arquivos Gulbenkian 1975, 1). Mais ainda, os efeitos desta iniciativa poderiam influenciar a participação de outros e contribuir para a reativação do agonizante mercado da arte contemporânea:

[...] a intervenção que a Fundação possa ter neste momento no capítulo de aquisições poderá ser exemplar e estimulante para uma reanimação do interesse pela compra de obras de arte contemporânea, sector em que a Fundação já desempenhou um papel pioneiro. (Arquivos Gulbenkian 1975, 1)

Com o deferimento da proposta, o Conselho de Administração criou, para o efeito, um fundo de $1000000 \$ 00$, ao qual foi ainda acrescentada uma verba de 250 mil escudos, destinada às compras previstas na exposição Figuração-Hoje. Por deliberação, foi ainda criada uma comissão consultiva para a seleção de obras. ${ }^{10}$

Para além da oportunidade de compra para a representação internacional da arte portuguesa, que à data se encontrava em fase de preparação, este acordo era fruto da estratégia de alianças institucionais e da afirmação da vocação mecenática da FCG.

Programada para integrar as manifestações culturais previstas para a visita oficial a França do Presidente da República Francisco da Costa Gomes e quando ainda se planificava a mostra que cobriria o período entre 1940 e 1970, a exposição foi subitamente cancelada e adiada pelo IV Governo Provisório. Inserida num ambiente político "quente", estes acontecimentos suscitaram uma polémica acesa na comunidade artística, que acabaria por ficar conhecida como «o caso da Exposição de Paris» (França 1975; França e Gonçalves 1975). Este episódio evidenciaria as tensões e reposicionamentos no novo xadrez artístico nacional, no qual também a FCG procurava um novo enquadramento político-institucional. Nesta estratégia coube à FCG manter as boas relações com antigos parceiros, tais como a SNBA e a AICA, esta última, fortemente atacada por alguns movimentos artísticos, como a APAP. O "Caso de Paris" teve um efeito deflagrador do debate em torno da estratégia nacional para as artes plásticas, convocando indiretamente a participação dos principais agentes artísticos e culturais do país, ambiente que viria a serenar sobretudo a partir de 1976, ano em que DavidMourão Ferreira assumiria a Secretaria de Estado da Cultura do I Governo Constitucional. ${ }^{11}$

\section{As exposições na Sociedade Nacional de Belas-Artes e as incorporações (1975-1977)}

23 Ainda antes de se imaginar o desfecho que a exposição de Paris viria a conhecer, aceitando o convite formulado pela direção da SNBA, a FCG acabaria por dar início a um 
período intensivo de aquisições em exposições oficiais da Sociedade, inaugurado, como referido, com a exposição Figuração-Hoje?

A exposição-inquérito pretendeu constituir-se numa convocatória à participação dos artistas que se encontravam a trabalhar em torno da figuração, destacando-se, sobretudo, pelo equilíbrio geracional e pela heterogeneidade do percurso individual dos artistas.

Apesar de os participantes terem denunciado o desfasamento do formato escolhido pelos programadores da exposição, que pressupunha o reativar de uma querela artística já ultrapassada, a exposição acabou por revelar a qualidade da maioria dos trabalhos, merecendo a atenção da FCG, que adquiriu uma obra a dez artistas participantes. ${ }^{12}$

A aposta recaiu, principalmente, em obras que revelavam a originalidade de jovens artistas que entretanto se apresentavam nos salões da SNBA (Mário Botas, Maria José Aguiar, Fátima Vaz ou Emília Nadal), muito embora a seleção pudesse ter sido ainda mais arrojada, deixando de fora obras de artistas emergentes como Julião Sarmento e Pedro Calapez, ou ainda as intervenções pictóricas de Helena Almeida, a instalação Porta, de Ana Vieira, ou o inquietante tríptico Deus de Clara Menéres. ${ }^{13}$

Esta seleção ia ao encontro do anunciado propósito de atualização do acervo, integrando, maioritariamente, obras de artistas que não se encontravam ainda representados, ao invés daquela que poderia ter sido a opção mais segura, de reforçar a presença de artistas com carreiras consolidadas, tais como Paula Rego, Mário Cesariny ou Cruzeiro Seixas. ${ }^{14}$

Apesar da heterogeneidade das obras adquiridas, sobressaem as propostas pessoais herdeiras de um figurativismo Pop. Digna de realce, no sentido da paridade de género, é a menor desproporcionalidade na aquisição de obras de arte de artistas mulheres.

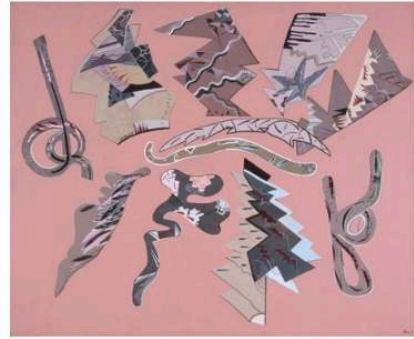

Fátima Vaz, Espelho Partido, 1974 (Tela, Tinta acrilica)

o Museu Calouste Gulbenkian Coleção Moderna

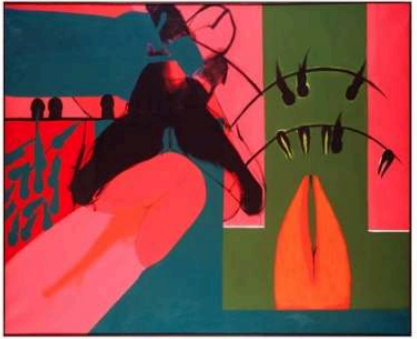

Maria José Aguiar, sem título, 1974 (Tela, Óleo)

O Museu Calouste Gulbenkian Coleção Moderna

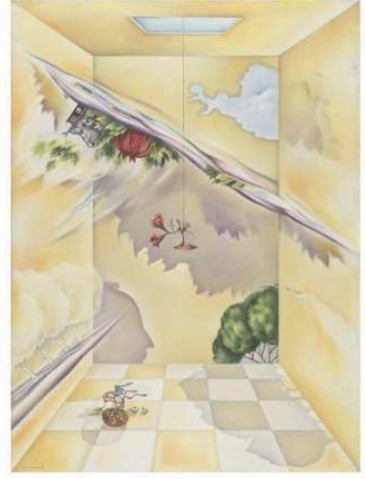

Emília Nadal, Decomposição VI, o Regresso, 1974, (Tela, Óleo)

○ Museu Calouste Gulbenkian/ Coleção Moderna

Fig. 1 - Algumas aquisições da Fundação Calouste Gulbenkian na exposição na Figuração-Hoje? (SNBA, 1975)

Imagens: Museu Calouste Gulbenkian/Coleção Moderna

Em moldes semelhantes, em abril de 1975, foi inaugurada na SNBA a exposiçãoinquérito Abstracção-Hoje? Tal como na anterior, as respostas insistiram na ideia de uma questão académica já ultrapassada. A repetição da participação de alguns artistas nestas duas primeiras mostras - uma dedicada à figuração e outra à abstração - veio 
comprovar, justamente, a diluição desses antagonismos, a permeabilidade e a transdisciplinaridade das práticas artísticas contemporâneas.

logo na seleção dos trabalhos de Graça Pereira Coutinho, Pedro Chorão e Teresa Magalhães, deixando, no entanto, de fora obras relevantes da produção artística coeva, como uma tapeçaria, fundida com a linguagem da pintura de Helena Lapas, as pinturas de variações monocromáticas de Fernando Calhau ou os padrões gráficos de Tela Dupla de E. M. Melo e Castro.

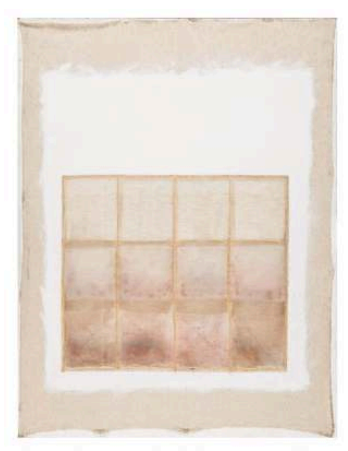

Graça Pereira Coutinho, Sem título, 1975 (Tecido, Tela e Madeira, Colagem)

Museu Calouste Gulbenkian Coleção Moderna

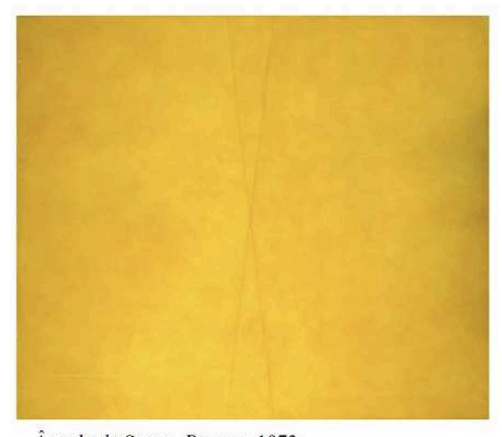

Ângelo de Sousa, Pintura, 1973, (Tela, Tinta acrílica)

○ Museu Calouste Gulbenkian Coleção Moderna

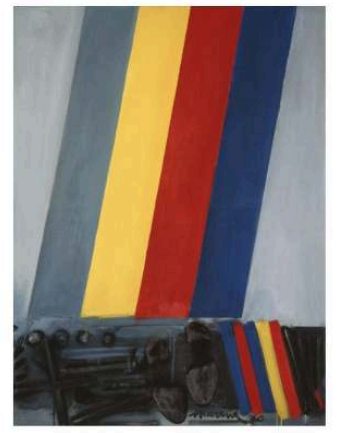

António Charrua, Bandeiras, 1970 , (Tela, Óleo)

(c) Museu Calouste Gulbenkian Coleção Moderna

Fig. 2 - Algumas aquisições da Fundação Calouste Gulbenkian na exposição na Figuração-Hoje? (SNBA, 1975)

Imagens: Museu Calouste Gulbenkian/Coleção Moderna

Passado aproximadamente um mês da realização destas compras, foi surpreendentemente cancelada a exposição de Paris, que havia fundamentado a realização do acordo. Apesar da vicissitude, o acordo entre a FCG e a SNBA continuou a vigorar com a aquisição de um novo conjunto de obras, logo em julho de 1975, no âmbito da exposição temática Colagem e Montagem.

Conforme a proposta da comissão ${ }^{18}$, a FCG adquiriu 14 obras, mais trabalhos do que nas exposições que a precederam, entre as quais uma colagem de António Sena, na qual explorava os contrastes cromáticos e o recurso a referências da contracultura de finais de 1960, como o poster. Eduardo Nery, através da manipulação ótica da técnica da colagem, explorava o cruzamento de referências visuais de diferentes temporalidades, numa nova fase do seu percurso artístico. A colagem As Tentações de Santo Antão, de Emília Nadal, refletia também essa vontade de confrontação e desestabilização de 
referências temporais. Do conjunto destaca-se também a obra Os Criminosos e as suas Propriedades, de Álvaro Lapa, que no pós-25 de abril, um período particularmente ativo do seu percurso criativo, aprofunda uma pintura eminentemente pessoal, onde conjuga a pintura, a escrita e a colagem. ${ }^{19}$

Esta seleção poderia ter contemplado outros trabalhos experimentais na fusão de técnicas, materiais e disciplinas artísticas, nomeadamente uma das intervenções sobre objetos de Carlos Nogueira (Banheira, 1872), as manipulações fotográficas de Victor Palla, da série Variações sobre o Rosto Humano, ou as pinturas-colagem de Luís Tinoco ou Julião Sarmento.

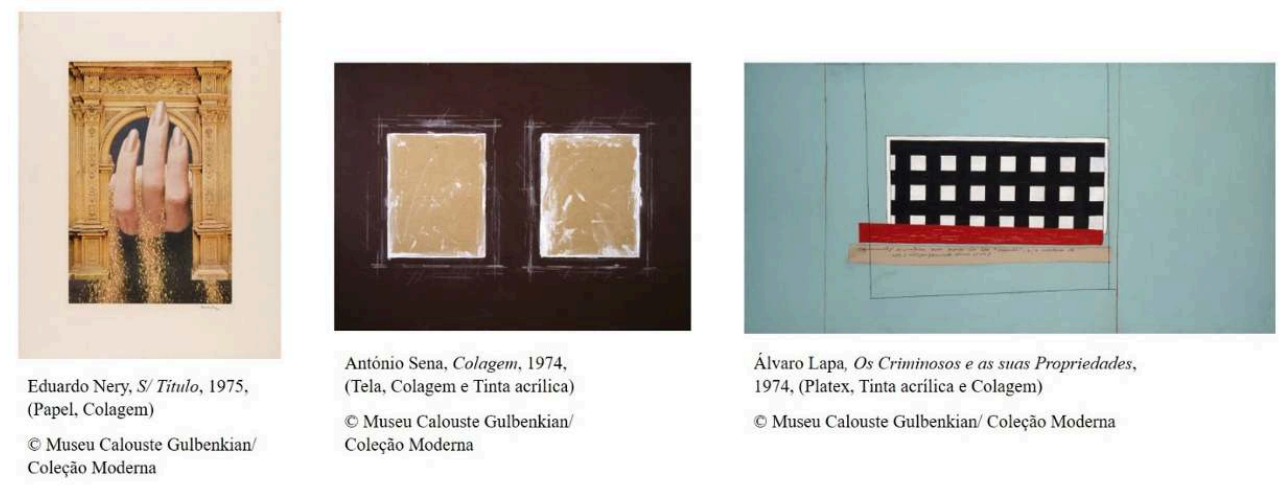

Fig. 3 - Algumas aquisições da Fundação Calouste Gulbenkian na exposição Colagem e Montagem (SNBA, 1975)

Imagens: Museu Calouste Gulbenkian/Coleção Moderna

Um novo momento aquisitivo teria lugar com o Salão de Abril de 1976, com a incorporação de dez obras apresentadas na mostra. Para o artista e crítico de arte Eurico Gonçalves tratou-se de um certame onde «sobrou insipiência a faltou maturidade» (Gonçalves 1976, s/p), no entanto, as compras realizadas pela FCG recaíram também em artistas que não se encontravam ainda representados na coleção. ${ }^{20}$ Destaque-se, entre estes, a aquisição da pintura de Carlos Calvet, herdeira do surrealismo e da arte metafísica, que contava já com quase três décadas de carreira e méritos artísticos reconhecidos, sobretudo desde finais de 1960; ou as obras de Lima de Carvalho e de Sérgio Pombo, que surgiam como derivas individualizadas da linguagem da Pop Art, que, em Pombo, assumiam uma clara alusão à recém-conquistada liberdade. Revelando acerto epocal, a pintura Matisse, Rothko, Ad Reinhardt (1974), da série homónima de Pires Vieira, explorava a linguagem minimalista, os limites tradicionais do suporte e da elementaridade da forma padronizada. 


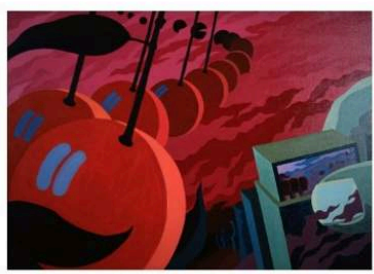

Carlos Calvet, Natureza Morta com Intervento 1976, (Tela, Tinta acrilica)

○ Museu Calouste Gulbenkian/ Coleção Moderna

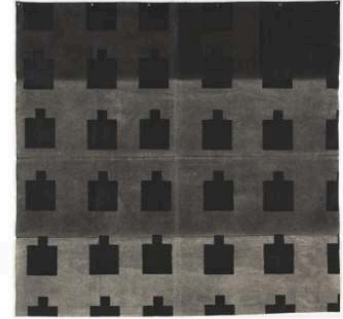

Pires Vieira, Matisse, Rothko, Ad Reinhardt, 1974, (Tela solta, Tinta acrilica) O Museu Calouste Gulbenkian/ Coleção

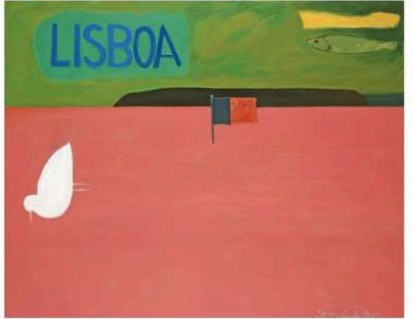

Sérgio Pombo, S/Titulo (Lisboa), 1975, (Tela, Tinta acrilica) O Museu Calouste Gulbenkian/ Coleção Moderna

Fig. 4 - Algumas aquisições da Fundação Calouste Gulbenkian no Salão de Abril (SNBA, 1976) Imagens: Museu Calouste Gulbenkian/Coleção Moderna

37 No decorrer da exposição 0 papel como Suporte na Expressão Plástica (1977), a FCG viria a adquirir, pela última vez, ao abrigo deste acordo, um conjunto de 18 obras. ${ }^{21} \mathrm{~A}$ quase totalidade dos trabalhos escolhidos recaía em artistas a quem já haviam sido adquiridas obras neste ciclo expositivo da SNBA (1975-1977) ou que já estavam representados na coleção. $^{22}$

A relevância das obras adquiridas é desigual, no entanto, destacam-se algumas incorporações importantes para a compreensão das práticas artísticas daqueles anos. ${ }^{23}$ Como reflexo da conjuntura experimental e transdisciplinar do período, pode ser vista a obra Separação de Helena Almeida, na qual a artista explorava e intervencionava, no suporte fotográfico, a performatividade do gesto. Do ponto de vista histórico, a serigrafia Slogans de José de Guimarães, traduzia o ambiente de intervenção cívica alcançado com a democracia. ${ }^{24}$ As referências à sociedade de consumo e à condição feminina, que faziam eco nesta década, estão presentes no desenho Papelotes de Emília Nadal.

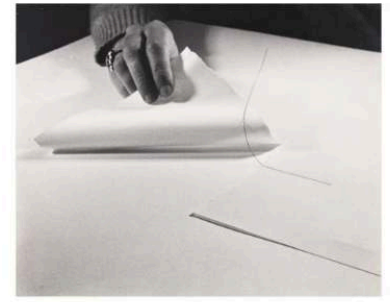

Helena Almeida, Separação, 1976 (Papel Fotografico, Fotografia)

○ Museu Calouste Gulbenkian/ Coleção Moderna
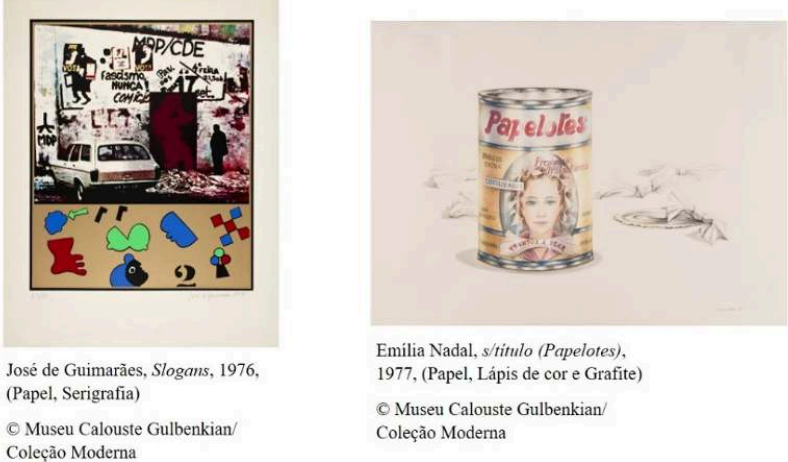

Fig. 5 - Algumas aquisições da Fundação Calouste Gulbenkian na exposição O Papel como Suporte na Expressão Plástica (SNBA, 1977)

Imagens: Museu Calouste Gulbenkian/Coleção Moderna

\section{Balanço do acordo}

Os anos que se seguiram à Revolução, sobretudo a partir de 1976, quando tomou posse o

I Governo Constitucional de Portugal, com Mário Soares como Primeiro-Ministro e 
David Mourão Ferreira como Secretário de Estado da Cultura, foram de intensa colaboração entre a FCG e o Estado na apresentação internacional de exposições de arte portuguesa contemporânea, inseridas no âmbito de visitas oficiais (Arte Portuguesa Contemporânea, 1976, Paris e Roma; Arte Portuguesa Contemporânea, 1976, Brasília, Rio de Janeiro, São Paulo). A organização destes eventos, assim como os programas de exposição de bolseiros e ex-bolseiros, em Lisboa e em Paris, no Centre Culturel Portugais (CCP), possibilitavam oportunidades únicas de atualização do acervo da FCG. ${ }^{25}$

40 A negociação do espólio artístico de Amadeo de Souza-Cardoso resultou, no ano de 1977, na aquisição de um conjunto de 22 obras e na doação de 26 obras do artista, impondo uma nova estratégia para a coleção e uma maior ponderação nas aquisições realizadas nos anos seguintes. ${ }^{26}$

41 Da oferta expositiva da SNBA (1975-1977) resultaria a incorporação de 62 obras de 44 artistas, sendo que mais de metade destes (25) não se encontravam ainda representados no acervo. Cumpria-se, portanto, ao nível da representatividade, os desígnios de aumentar a presença de artistas contemporâneos no acervo.

42 As opções de compra evidenciam também a forte presença de artistas bolseiros, exbolseiros ou subvencionados pela FCG (21), dez dos quais em atividade durante este período. ${ }^{27}$ Note-se ainda que foram sobretudo estes os artistas a quem a Fundação comprou mais do que uma obra no âmbito do acordo. 0 incremento da ação mecenática da FCG no auxílio aos artistas (Candeias 2009) encontra justificação, além da já referida estratégia de afirmação artística da FCG deste período, na real necessidade de suprir as dificuldades económicas dos artistas, profundamente agravadas pela estagnação do mercado (Silva 2009).

No que se refere aos suportes e disciplinas artísticas, as escolhas recaíram sobretudo na categoria de pintura (29), seguida do desenho (20) e da gravura (7), evidenciando uma relação direta com oferta disponibilizada nesses certames. ${ }^{28}$ No entanto, como foi mencionado, foi negligenciada a oportunidade de incluir outras obras marcantes no contexto das práticas artísticas daqueles anos, como os Ambientes de Ana Vieira, as intervenções críticas de Clara Menéres, entre outras. Na escultura, foram apenas incorporadas duas obras, de Helder Batista e Virgílio A. Domingues, havendo, no caso da pequena escultura Conluio de Domingues, um registo anti-monumento, satírico e interventivo, reflexo do período histórico vivido. Aliás, o ambiente político e social que atingia o país faria eco na produção artística da década, como de resto evidenciam as obras de Henrique Manuel, de Sérgio Pombo e de José de Guimarães, com claras alusões à Revolução de Abril, ou, mais subtilmente, a pintura de António Sena. ${ }^{29}$ Neste âmbito, poderia ter sido ainda adquirido um interessante conjunto de colagens Voz das Paredes, ou Paredes do Alentejo, de Manuel Filipe, alusivas ao movimento espontâneo e autodidata de muralismo surgido no pós-25 de Abril.

As questões emergentes relacionadas com a condição e emancipação feminina estão também presentes nestas aquisições, nomeadamente nas obras de Maria José Aguiar, Matilde Marçal e Emília Nadal. ${ }^{30}$

o experimentalismo, o caráter processual da arte e a transdisciplinaridade, eixos fundamentais das práticas artísticas deste período, foram também postos em evidência nas propostas artísticas de Graça Pereira Coutinho, Pires Vieira e Helena Almeida, respetivamente. 


\section{Considerações finais}

A entrada do regime democrático em Portugal obrigou à reorganização dos poderes e ao reposicionamento no mundo da arte português. $O$ processo revolucionário originou uma nova teia de intermediações entre agentes que participavam ativamente na redefinição de uma estratégia nacional para as artes plásticas e visuais. É neste ambiente político e social do PREC que se estreitam as relações institucionais e comerciais entre a FCG e a SNBA, materializadas na celebração de um inédito acordo de compras de obras de arte em exposições da SNBA.

Estrategicamente, a FCG via na afirmação da sua vocação mecenática a garantia de autonomia e de preponderância no meio artístico português. Do lado da SNBA, que agregava grupos de artistas particularmente ativos nos debates artísticos da época, as apreensões recaíam, sobretudo, em aspetos de ordem económica. É deste encontro de necessidades que o acordo nasce, mas não só. 0 duro período de estagnação do mercado e da diminuição da oferta expositiva tornava urgente o auxílio da FCG aos artistas, quer pela aquisição de obras de arte, quer pela atribuição de bolsas e de subsídios de investigação. $\mathrm{O}$ acordo permitiria acudir aos artistas, muitos deles bolseiros da Fundação, assim como serviria de estímulo para o mercado e para o colecionismo.

Mais ainda, no âmbito da diplomacia, a abertura da arte portuguesa contemporânea aos círculos artísticos internacionais, sobretudo europeus, era entendida como estratégica para a apresentação de uma nova imagem do país, democrático e cosmopolita. Esta premissa exigia o recurso a um acervo heterogéneo e suficientemente representativo da produção artística contemporânea para apresentar além-fronteiras, que só o acervo da FCG poderia garantir, face à fraca representatividade dos artistas contemporâneos nas coleções do Estado. A organização de uma exposição portuguesa de périplo internacional corroborava a necessidade de reforço e atualização do acervo.

Este acordo de compras viria a ser o motor de desenvolvimento da Coleção Moderna nos anos de mudança de regime político. O triénio (1975-1977) que mediou o acordo de compras estabelecido entre as instituições, correspondeu quase à totalidade das aquisições de arte portuguesa realizadas pela FCG em exposições de arte. Embora não corresponda ao período mais intenso do desenvolvimento do acervo, este acordo foi, tendo em conta o momento político, económico e social que se vivia, um acordo de aquisições excecional e sem precedentes nos moldes de relacionamento comercial da FCG com o circuito expositivo, não se conhecendo nenhum outro protocolo semelhante formalizado com instituições congéneres.

50 Analisando as opções de compra, torna-se evidente, por um lado, o acerto de algumas escolhas, que refletem, não só o ambiente de intervenção cívica que se vivia - no âmbito político, artístico e ao nível da igualdade de género - como, por outro, evidenciam uma tímida recetividade à transdisciplinaridade, às práticas experimentais e conceptuais características da década. Esta prudência aquisitiva é denunciada, sobretudo, pelas obras que ficaram de fora, mas também pela prevalência da disciplina tradicional da pintura face a outros suportes.

51 No conjunto das obras adquiridas nestes certames, enfatiza-se: a) algumas obras de destaque da coleção, que têm sido apresentados nas sucessivas montagens permanentes, em empréstimos e representações internacionais; b) um conjunto abrangente de artistas bolseiros e ex-bolseiros da Fundação, que, doravante teriam um 
papel importante na internacionalização da arte portuguesa deste período, assunto que carece de estudo aprofundado. Em aberto fica também uma investigação mais sistemática ao período "quente" de 1975, focado nos movimentos, nos grupos de artistas e nos seus posicionamentos divergentes sobre o futuro da política artística do país. A colaboração da FCG com a Secretaria de Estado da Cultura na estratégia de internacionalização artística merece, igualmente, maior desenvolvimento.

\section{BIBLIOGRAFIA}

"Fundação Gulbenkian. A Administração Dificulta o Saneamento." 1975. Diário de Lisboa, 13 mai., p. 7.

Abstracção-Hoje? [catálogo de exposição]. 1975. Lisboa: Sociedade Nacional de Belas-Artes.

Afonso, Lígia. 2018. “Dias de Saída. O SNI e a Bienal de São Paulo na Génese da Internacionalização Contemporânea da Arte Portuguesa (1951-1973). Tese de doutoramento em História da Arte, especialidade de Museologia e Património Artístico, Faculdade de Ciências Sociais e Humanas, Universidade Nova de Lisboa.

Afonso, Luís Urbano, e Alexandra Fernandes. 2019. “Um Mercado Regional e Doméstico.” In Mercados da Arte, 197-211. Lisboa: Edições Sílabo.

Arquivos Gulbenkian. 1975a. Carta de Rui Mário Gonçalves a Artur Nobre de Gusmão, Lisboa (23 jan. 1975), Arquivos Gulbenkian, SBA 01799.

Arquivos Gulbenkian. 1975b. Acta n.ำ13/75 Reunião do Conselho de Administração (18 fev. 1975), Arquivos Gulbenkian, SBA 01799.

Arquivos Gulbenkian. 1975c. Apontamento do Serviço de Belas-Artes. Proposta de Aquisição de Obras em Próximas Exposições da Sociedade Nacional de Belas-Artes, Lisboa (18 fev. 1975), Arquivos Gulbenkian, SBA 01799.

Arquivos Gulbenkian. 1975d. Nota Sobre as Representações da Fundação Calouste Gulbenkian na Direcção-Geral da Cultura Popular e Espectáculos do Ministério da Comunicação Social (3 jun. 1975), SEM 00137.

Arquivos Gulbenkian. 1977. Apontamento do Serviço de Belas-Artes Inf. $n . \cong 400 / 77$ (16 set. 1977), Arquivos Gulbenkian, SBA 01799.

Candeias, Ana Filipa. 2009. “Fotografia, Performance, Imagem em Movimento. Os Artistas e os Novos Meios em Portugal». In Anos 70. Atravessar Fronteiras [catálogo de exposição], 32-39. Lisboa: Fundação Calouste Gulbenkian.

Colagem e Montagem [catálogo de exposição]. 1975. Lisboa: Sociedade Nacional de Belas-Artes.

Duarte, Adelaide. 2017. Da Coleção ao Museu. o Colecionismo Privado de Arte Moderna e Contemporânea em Portugal. Vol. 6. Coleção Estudos de Museu. Casal de Cambra: Caleidoscópio e Direção-Geral do Património Cultural.

Ferreira, José Medeiros. 2007. “A Instituição.” In Fundação Calouste Gulbenkian. Cinquenta anos 1956-2006, 69-163. Lisboa: Fundação Calouste Gulbenkian. 
Figuração-Hoje? [catálogo de exposição]. 1975. Lisboa: Sociedade Nacional de Belas-Artes.

França, José Augusto, e Rui Mário Gonçalves. 1975. "Elementos para a Cronologia do 'Caso da Exposição de Paris'." Colóquio. Artes, 2. érie, n.ำ 24 (out.): 40-41.

França, José-Augusto. 1975. "Folhetim Artístico. No rescaldo do 'Caso da Exposição de Paris'.” Jornal Novo, 10 jul., p. 7.

Gonçalves, Eurico. 1976. "Salão de Abril. Sobrou Insipiência onde Faltou Maturidade." Flama, 28 mai., s/p.

Gonçalves, Rui Mário. 1975. “Agitação e Desperdícios.” Colóquio. Artes, 2. aㅗ'rie, n.o 24 (out.): 32-39.

Macedo, Rita. 2009. “1968-1974 Renovação na Continuidade.” In Anos 70. Atravessar Fronteiras [catálogo de exposição], 18-25. Lisboa: Fundação Calouste Gulbenkian.

Maurício, Ana Fabíola. 2016. "30 Years of Culture, Art and Metamorphoses. The Modern Art Centre of the Calouste Gulbenkian Foundation and the Reshaping of Lisbon's Culturalscape.” Tese de doutoramento em Estudos de Cultura, Universidade Católica Portuguesa.

Nogueira, Isabel. 2009. “Artes Plásticas e Pensamento Crítico em Portugal nos anos Setenta e Oitenta. Problemáticas da Operacionalidade dos Conceitos de Vanguarda e de Pós-modernismo." Tese de doutoramento em Belas-Artes (Ciências da Arte), Faculdade de Belas-Artes, Universidade de Lisboa.

O Papel como Suporte na Expressão Plástica [catálogo de exposição]. 1977. Lisboa: Sociedade Nacional de Belas-Artes.

Oliveira, Leonor de. 2013. "Fundação Calouste Gulbenkian: Estratégias de Apoio e Internacionalização da Arte Portuguesa 1957-1969.” Tese de doutoramento em História da Arte, Faculdade de Ciências Sociais e Humanas, Universidade Nova de Lisboa.

Pena, Gonçalo. 1994. “Instituições, Galerias e Mercado.” In Anos 60, anos de Ruptura. Uma Perspectiva da Arte Portuguesa nos anos Sessenta [catálogo de exposição], s/p. Lisboa: Livros Horizonte.

Perdigão. José Azeredo. 1976. Relatório do Presidente, vol. 6, jan. 1972-dez. 1974, Lisboa: Fundação Calouste Gulbenkian.

Pinharanda, João Lima. 1995. “Anos 70. Um Tempo de Passagem." In História da Arte Portuguesa. Do Barroco à Contemporaneidade, ed. Paulo Pereira, vol. III, 102-111. Lisboa: Círculo de Leitores.

Pinho, Elsa. 2013. “A Evolução das Coleções Públicas em Contexto Democrático. Políticas de Incorporação e Vetores de Crescimento nos Museus de Arte da Administração Central do Estado (1974-2010)." Tese de doutoramento em Belas-Artes (Ciências da Arte), Faculdade de Belas-Artes, Universidade de Lisboa.

Ribeiro, António Pinto. 2007. “Arte.” In Fundação Calouste Gulbenkian. Cinquenta anos 1956-2006, 237-408. Lisboa: Fundação Calouste Gulbenkian.

RTP Arquivos. 1974. Programa televisivo Sabe o que é a Sociedade Nacional de Belas Artes?, RTP, 15 jul 1974. https://arquivos.rtp.pt/conteudos/sabe-o-que-e-a-sociedade-nacional-de-belas-artes Salão de Abril [catálogo de exposição]. 1976. Lisboa: Sociedade Nacional de Belas-Artes. Silva, Helena Vaz da. 1975. "Os Artistas Frente a Frente. A Arte para o Povo ou o Povo para a Arte?" Expresso, 31 mai., s/p. 
Silva, Raquel Henriques da. 2016. "A Coleção do Centro de Arte Moderna da Fundação Calouste Gulbenkian; Contributos de Artistas-bolseiros." In Histórias da Arte em Coleções: Modos de Ver e Exibir em Brasil e Portugal, 171-186. Rio de Janeiro: Rio Book's.

Silva. Raquel Henriques da, Ana Filipa Candeias, e Ana Ruivo, eds. 2009. Anos 70. Atravessar Fronteiras [catálogo de exposição]. Lisboa: Fundação Calouste Gulbenkian.

Silva. Raquel Henriques da. 2009. “Os Anos 70 depois do 25 de Abril." In Anos 70. Atravessar Fronteiras [catálogo de exposição], 26-31. Lisboa: Fundação Calouste Gulbenkian.

Silva. Raquel Henriques da. 2014. “A Colecção do CAM, um Desígnio Nacional: Divulgar, Partilhar e Valorizar a Arte Moderna e Contemporânea." In 30 Anos-Years: Centro de Arte Moderna Fundação Calouste Gulbenkian, ed. Nuno Grande, 118-127. Lisboa: Fundação Calouste Gulbenkian. Centro de Arte Moderna.

Skapinakis, Nikias. 1975. "Carta Aberta ao Comandante Correia Jesuíno.” A Capital, 26 mai., s/p.

Sousa. Ernesto. 1977. Carta de Ernesto de Sousa à SNBA, 21 jul. http://www.ernestodesousa.com/ bibliografia/o-papel-das-beeelaaass-aarrteeess

Tavares, Cristina Azevedo. 2006. A Sociedade Nacional de Belas-Artes. Um Século de História e de Arte, Vila Nova de Cerveira: Fundação da Bienal de Vila Nova de Cerveira.

Varela. Raquel, António Simões do Paco, Joana Alcantara, e Pedro Almeida Ferreira. 2015.

“Autogestão e Crise Econômica na Revolução Portuguesa (1974-1975).” Sociologia \& Antropologia, vol. 5, n.ำ 2 (mai.-ago.), 479-499.

\section{NOTAS}

1. Integravam o Conselho Técnico Fernando Conduto, Joaquim Rodrigo, Jorge Vieira, Luís Dourdil, Sena da Silva, Artur Bual, João Abel Manta, Manuel Taínha, Querubim Lapa e Marcelino Vespeira.

2. Exemplos disso são as aquisições das obras de Paula Rego (Manifesto (for a Lost Cause), 1965) e de Júlio Pomar (Entrada de Touros, 1964; Campinos, 1963), apresentadas nas respetivas exposições individuais na Galeria de Arte Moderna da Sociedade.

3. A FCG colaborou com o SNI na organização das exposições Portugal de Hoje (Rio de Janeiro, 1965) e Arte Portuguesa. Pintura e Escultura do Naturalismo aos Nossos Dias (Bruxelas, Paris e Madrid, 1967-1968).

4. Para colmatar algumas lacunas do acervo de arte portuguesa contemporânea, com o intuito de as integrar na exposição itinerante internacional de arte portuguesa de 1967-1968, foram adquiridas à SNBA obras representativas de Joaquim Rodrigo, Artur Rosa, Manuel Baptista e António Palolo.

5. Em 1975 e no decurso dos processos de nacionalização da banca, a coleção do banqueiro Jorge de Brito (Banco Intercontinental Português) foi arrolada, no seguimento da insolvência do banco. A coleção do Banco Pinto de Magalhães transitaria, em 1978, para a União de Bancos Portugueses. Neste período, Jorge de Brito e Manuel Fernandes Magalhães terão, alegadamente, tentado exportar ilicitamente algumas obras das suas coleções destinadas ao mercado internacional (Pinho 2013). O empresário e colecionador Augusto Abreu dispersaria também o núcleo internacional sua coleção no pós-25 de Abril (Duarte 2017; Afonso e Fernandes 2019).

6. Poucos meses após a Revolução, numa reportagem da RTP sobre a SNBA, Arlindo Vicente, reformador dos Estatutos da SNBA, fez um apelo à sociedade civil para apoiar financeiramente a Sociedade (RTP Arquivos 1974). 
7. Criada depois da Revolução, ainda em 1974, a CCAP, para além dos representantes da FCG, era constituída pelo MCS, através da DGCPE, pelo Ministério dos Negócios Estrangeiros (MNE), através da Direcção-Geral dos Assuntos Culturais (DGAC), pelo Ministério da Educação e Cultura (MEC), pela Direcção-Geral da Cultura e Educação Permanente (DGCEP), pela Secretaria de Estado da Habitação e Urbanismo (SEHU), pelas Escolas Superiores de Belas-Artes de Lisboa e do Porto, pela SNBA, pela Cooperativa «Gravura», pela Secção Portuguesa da Associação Internacional de Críticos de Arte (AICA), pela Cooperativa Árvore e pelo MDAP. Mais tarde, em 1975 veio a integrar a Comissão Executiva dos Trabalhadores da FCG, o INATEL, a Associação Portuguesa dos Artistas Plásticos (APAP). No âmbito desta comissão, que integrava várias fações, reforçar-se-ia, no decurso dos acontecimentos ligados ao designado "caso de Paris" (vide infra), a aliança entre velhos parceiros: FCG, SNBA e AICA.

8. Perspetivava-se ainda o périplo internacional da exposição pela Europa de leste e ocidental.

9. O patrocínio avultado desta exposição deixa antever uma manobra política por parte FCG, interessada em reforçar a sua posição junto dos novos poderes políticos.

10. A comissão integrava os três representantes signatários da proposta (diretor e assistente de direção do SBA e diretor do Serviço de Exposições e Museografia - SEM); dois representantes designados pela SNBA; e dois críticos da AICA, devendo um deles ser José-Augusto França, diretor da revista Colóquio. Artes, da chancela da FCG.

11. A complexidade destes assuntos, a diversidade dos agentes envolvidos e dos seus posicionamentos carece de estudo aprofundado. Para uma maior panorâmica da ebulição do período veja-se Gonçalves (1975), Silva (1975) e Skapinakis (1975).

12. A comissão de seleção foi constituída pelos três responsáveis dos serviços de Belas-Artes e Exposições da FCG, por Rui Mário Gonçalves, Helder Baptista pela SNBA, José-Augusto França e Salette Tavares pela Secção Portuguesa da AICA. A seleção dos colaboradores institucionais para estas comissões é sintomática do reconhecimento e idoneidade que a Fundação conferia às duas instituições, bem como do reforço da cooperação com antigos parceiros.

13. Desta seleção, foram ainda excluídas as propostas conceptuais e objetuais de Sam e Tomaz Vieira, alinhadas com o experimentalismo da época.

14. Foram ainda adquiridos trabalhos a Virgílio Domingues, Luis Dourdil, Henrique Manuel, Rocha de Sousa, Eduardo Nery e Matilde Marçal.

15. Esta comissão de seleção foi constituída pelos responsáveis da FCG, por Rocha de Sousa e Virgílio Domingues pela SNBA, e José-Augusto França e Rui Mário Gonçalves pela AICA.

16. Pela primeira vez foram também integradas no acervo obras de Vítor Fortes, Teresa Magalhães, Pedro Chorão e Graça Pereira Coutinho.

17. A representatividade de Manuel Baptista e de Eurico Gonçalves foi também reforçada, muito embora os trabalhos adquiridos revelassem alguma continuidade com as linhas de trabalho desenvolvidas nas obras previamente adquiridas.

18. A comissão de seleção foi constituída pelos responsáveis da FCG, por Henrique Manuel e Virgílio Domingues pela SNBA, José-Augusto França e um outro elemento da secção portuguesa da AICA.

19. Foram ainda adquiridas obras de Teresa Magalhães, Mário Botas, Vítor Fortes, Eurico Gonçalves, Guilherme Parente, Maria Gabriel, Pedro Chorão, Renée Gagnon, Ana Leão e Helena Sá, sendo que as três últimas correspondiam a estreias no acervo.

20. Passariam a integrar o acervo: Pires Vieira, Carlos Calvet, Rogério Amaral, Tomás Vieira, Nuno San-Payo, Sérgio Pombo e Lima de Carvalho. Maria Gabriel, Rocha de Sousa e Rui Filipe já se encontravam anteriormente representados.

21. O administrador Pedro Tamen recomendou, internamente, a elaboração de um parecer sobre um futuro plano de aquisições, que acabou por ser sucessivamente adiado (Arquivos Gulbenkian 1977). Em 1981, Tamen viria a cancelar o saldo disponível para este fundo de aquisições. 
22. A exceção recaía nas serigrafias de João Bento de Almeida, com referências à Pop Art inglesa de Patrick Caulfield e de Luiz Morais (não localizada), e num desenho de Carlos Duarte.

23. Esta exposição foi também palco de uma pequena contenda entre a Direção da SNBA e Ernesto de Sousa, que motivaram algumas críticas à atividade da SNBA (Sousa 1977). Boa parte dos expositores nestas mostras da SNBA figuraram também na Alternativa Zero (Galeria Nacional de Arte Moderna, 1977), exposição organizada pelo crítico e artista.

24. Este trabalho pertencia a uma série de gravuras que o artista realizou, enquanto bolseiro da FCG, dedicadas ao 25 de Abril 1974 e ao 1. de Maio.

25. Este programa de exposições de bolseiros e ex-bolseiros da FCG teve início em 1970, com a exposição de Nadir Afonso no CCP, seguida, no ano seguinte, da exposição de obras de exbolseiros da Fundação Calouste Gulbenkian, em Canning House (Londres). Posteriormente, realizaram-se várias exposições individuais de bolseiros no CCP, na segunda metade da década, em Lisboa.

26. Esta importante incorporação está na origem de uma outra decisão, anunciada dois anos mais tarde: a construção do Centro de Arte Moderna (1984), que viria a redefinir a estratégia da coleção.

27. Foram os casos de Álvaro Lapa, António Charrua, Graça Pereira Coutinho, José de Guimarães, Renée Gagnon, Sérgio Pombo, Emília Nadal, Teresa Magalhães, Pedro Chorão e Matilde Marçal.

28. Foram ainda incorporadas uma tapeçaria de Flávia Monsaraz e uma fotografia de Helena Almeida.

29. O desenho e as artes gráficas, ao serviço dos mecanismos de intervenção, foram amplamente explorados neste período, correspondendo «à componente mais específica das "artes de Abril"» (Silva 2009, 27).

30. Apesar de uma maior participação feminina nos eventos expositivos, a aquisição de obras de mulheres artistas correspondeu apenas a $25 \%$ do total das obras incorporadas.

\section{RESUMOS}

A Coleção Moderna do Museu Calouste Gulbenkian - a mais relevante coleção de arte moderna e contemporânea portuguesa, iniciada em 1957 e tutelada pela Fundação Calouste Gulbenkian (FCG) - carece de estudo aprofundado sobre a sua constituição e desenvolvimento, ao longo de mais de 60 anos de incorporações. A análise à evolução deste acervo, no momento subsequente à Revolução de 25 de Abril de 1974, período ainda pouco investigado no âmbito da historiografia da arte e do colecionismo em Portugal, torna este estudo ainda mais oportuno. Da pesquisa realizada nos fundos dos Arquivos Gulbenkian e no inventário da coleção concluiu-se que, entre os anos de 1975 e 1977, ocorreu algo sem precedentes no desenvolvimento do acervo: um acordo de compra de obras de arte contemporânea entre a FCG e a Sociedade Nacional de Belas-Artes (SNBA), em exposições organizadas pela Sociedade. No período "quente" e instável que o país atravessava, estas duas instituições, fundamentais no desenvolvimento do meio artístico português, estreitavam laços de cooperação. Para além da aliança institucional, o acordo garantia ainda o apoio financeiro aos artistas e à SNBA, num período de estagnação do mercado da arte nacional. Durante estes anos, o desenvolvimento da coleção foi quase exclusivamente garantido pelas aquisições realizadas nestas exposições da SNBA, reforçando a representatividade da produção contemporânea e de artistas cujas carreiras se projetariam na década seguinte. A curta duração 
deste acordo estará certamente relacionada com a pacificação do ambiente político-social e com o consequente processo de reorganização artística do país.

The Modern Collection of the Calouste Gulbenkian Museum - the most relevant collection of modern and contemporary Portuguese art, started in 1957 by the Calouste Gulbenkian Foundation (FCG) - needs an in-depth study of its development, over more than 60 years of art collecting. The analysis of the evolution of this collection, in the moment following the Revolution of April 25th,1974, a period poorly investigated in the scope of the historiography of art and collecting in Portugal, which makes this study opportune. Based on the research carried out in the Gulbenkian Archives and in the collection inventory, it was concluded that, between the years 1975 and 1977, something unprecedented occurred in the development of the collection: an agreement for the acquisition of contemporary art works between the FCG and the Sociedade Nacional de Belas-Artes (National Society of Fine Arts) (SNBA), in exhibitions organized by the Society. In the "hot" and unstable period that the country was going through, these two institutions, fundamental in the development of the Portuguese artistic environment, strengthened cooperation. In addition to the institutional alliance, the agreement also guaranteed financial support to artists and to SNBA, in a period of stagnation of the national art market. During these years, the development of the collection was almost exclusively guaranteed by the acquisitions made in the SNBA exhibitions, reinforcing the representativeness of contemporary production and of artists whose careers would be significant in the following decade. The short duration of this agreement was certainly related to the pacification of the political-social environment and the consequent process of artistic reorganization of the country.

\section{ÍNDICE}

Palavras-chave: Museu Calouste Gulbenkian, Sociedade Nacional de Belas-Artes, Coleção Moderna do Museu Calouste Gulbenkian, política de incorporações, formação de coleções Keywords: Calouste Gulbenkian Museum, Modern Collection of the Calouste Gulbenkian Museum, collecting policy, formation of collections

\section{AUTOR}

\section{FILIPA COIMBRA}

É doutoranda em História da Arte - Museologia e Património Artístico na Faculdade de Ciências Sociais e Humanas da Universidade Nova de Lisboa e investigadora do Instituto de História da Arte da mesma Universidade, com uma bolsa (2019-) da Fundação para a Ciência e a Tecnologia (FCT). Mestre em Crítica de Arte e Arquitetura (2013) pelo Colégio das Artes da Universidade de Coimbra e licenciada em História da Arte (2008) pela Faculdade de Letras da mesma Universidade. Foi investigadora no projeto "História das Exposições de Arte da Fundação Calouste Gulbenkian Catálogo Online” (2014-2018) do Instituto de História da Arte. Tem como tema de investigação a Coleção Moderna do Museu Calouste Gulbenkian.

Instituto de História da Arte, Faculdade de Ciências Sociais e Humanas, Universidade de Lisboa, Colégio Almada Negreiros, Campus de Campolide, sala 347, 1070-312 Lisboa, Portugal, filipamcvcoimbra@gmail.com 